\title{
Communication \\ Enzymatic Hydrogen Electrosynthesis at Enhanced Current Density Using a Redox Polymer
}

\author{
John C. Ruth ${ }^{1}$, Fabian M. Schwarz ${ }^{2}$, Volker Müller ${ }^{2}$ and Alfred M. Spormann ${ }^{1,3, *}$ \\ 1 Department of Chemical Engineering, Stanford University, Stanford, CA 94305, USA; jruth@stanford.edu \\ 2 Department of Molecular Microbiology and Bioenergetics, Johann Wolfgang Goethe University, \\ 60438 Frankfurt am Main, Germany; f.schwarz@bio.uni-frankfurt.de (F.M.S.); \\ vmueller@bio.uni-frankfurt.de (V.M.) \\ 3 Department of Civil and Environmental Engineering, Stanford University, Stanford, CA 94305, USA \\ * Correspondence: spormann@stanford.edu
}

check for updates

Citation: Ruth, J.C.; Schwarz, F.M.; Müller, V.; Spormann, A.M. Enzymatic Hydrogen

Electrosynthesis at Enhanced Current Density Using a Redox Polymer. Catalysts 2021, 11, 1197. https:// doi.org/10.3390/catal11101197

Academic Editors: Evangelos Topakas, David D. Boehr and Roland Wohlgemuth

Received: 29 August 2021 Accepted: 27 September 2021 Published: 30 September 2021

Publisher's Note: MDPI stays neutral with regard to jurisdictional claims in published maps and institutional affiliations.

Copyright: (c) 2021 by the authors. Licensee MDPI, Basel, Switzerland. This article is an open access article distributed under the terms and conditions of the Creative Commons Attribution (CC BY) license (https:// creativecommons.org/licenses/by/ $4.0 /)$.

\begin{abstract}
High-temperature tolerant enzymes offer multiple advantages over enzymes from mesophilic organisms for the industrial production of sustainable chemicals due to high specific activities and stabilities towards fluctuations in $\mathrm{pH}$, heat, and organic solvents. The production of molecular hydrogen $\left(\mathrm{H}_{2}\right)$ is of particular interest because of the multiple uses of hydrogen in energy and chemicals applications, and the ability of hydrogenase enzymes to reduce protons to $\mathrm{H}_{2}$ at a cathode. We examined the activity of Hydrogen-Dependent $\mathrm{CO}_{2}$ Reductase (HDCR) from the thermophilic bacterium Thermoanaerobacter kivui when immobilized in a redox polymer, cobaltocene-functionalized polyallylamine (Cc-PAA), on a cathode for enzyme-mediated $\mathrm{H}_{2}$ formation from electricity. The presence of Cc-PAA increased reductive current density 340-fold when used on an electrode with HDCR at $40{ }^{\circ} \mathrm{C}$, reaching unprecedented current densities of up to $3 \mathrm{~mA} \cdot \mathrm{cm}^{-2}$ with minimal overpotential and high faradaic efficiency. In contrast to other hydrogenases, T. kivui HDCR showed substantial reversibility of CO-dependent inactivation, revealing an opportunity for usage in gas mixtures containing $\mathrm{CO}$, such as syngas. This study highlights the important potential of combining redox polymers with novel enzymes from thermophiles for enhanced electrosynthesis.
\end{abstract}

Keywords: hydrogen-dependent $\mathrm{CO}_{2}$ reductase; redox polymer; cobaltocene; enzymatic electrosynthesis; hydrogen evolution; carbon monoxide

\section{Introduction}

Rising global temperatures and their resulting environmental effects are leading to an urgent transition towards renewable energies [1]. Converting sustainably generated energies to a chemical form is desirable and important for long-term energy storage and transport [2]. A variety of small, high-energy molecules are promising target products for this conversion, including hydrogen and formate, because only simple, two-electron reduction reactions are required for their production and their usability in existing technologies [3-5]. Hydrogen is particularly interesting due to its high energy content, low redox potential, and usage in a wide variety of industrial processes [4,6].

Enzymes, such as hydrogenases and formate dehydrogenases, are promising catalysts for conversion of electrical energy to storable chemical energy, due to their high selectivities and activities [3,7]. In particular, Hydrogen-Dependent $\mathrm{CO}_{2}$ Reductase (HDCR) is an enzyme of interest for both enzymatic formate and hydrogen synthesis as a result of its high turnover rates and selectivity at high temperatures [8-11]. In vivo, HDCR catalyzes the simultaneous oxidation of $\mathrm{H}_{2}$ to protons and reduction of $\mathrm{CO}_{2}$ to formate in the methyl branch of the Wood-Ljungdahl pathway of the two acetogenic bacteria Acetobacterium woodii and Thermoanaerobacter kivui. HDCR-like gene clusters were also found in the genome of different organisms but biochemical evidence of purified HDCRs was so far only given for the two mentioned acetogens. HDCR from Thermoanaerobacter kivui is $\mathrm{O}_{2}$-sensitive 
and contains a hydrogenase and a formate dehydrogenase subunit, linked by two $4 \mathrm{Fe}-4 \mathrm{~S}$ cluster-containing electron transfer subunits [10]. This HDCR is a Fe-Fe hydrogenase with two Fe atoms in its active site, which has the highest measured hydrogen production activities among hydrogenases. Other Fe-Fe hydrogenases were previously shown to be irreversibly inactivated by both $\mathrm{O}_{2}$ and carbon monoxide (CO) [12]. Purified HDCR from thermophilic T. kivui catalyzes hydrogen evolution from formate at a specific activity of $930 \mu \mathrm{mol}$ hydrogen $\cdot \mathrm{min}^{-1} \cdot \mathrm{mg}^{-1}$ at $60{ }^{\circ} \mathrm{C}[10]$. This enzyme is stable above $37{ }^{\circ} \mathrm{C}$ and has its optimal activity between 60 and $70{ }^{\circ} \mathrm{C}$. Interestingly, HDCR from the mesophilic acetogen Acetobacterium woodii is completely tolerant of $\mathrm{CO}$, regaining full activity after an initial inhibition [8]. Reversible inactivation after $\mathrm{CO}$ addition to this Fe-Fe hydrogenase is unusual, as Fe-Fe hydrogenases are typically irreversibly inactivated by $\mathrm{CO}$ via binding to the distal Fe [12]. CO-insensitivity in enzymatic catalysts is desirable in many industrial processes, such as those involving syngas. While the HDCR of $A$. woodii has displayed reactivation after exposure to $\mathrm{CO}, \mathrm{CO}$ sensitivity of the heat stable HDCR of T. kivui, which has significantly higher turnover rates and also contains an Fe-Fe hydrogenase, has not been investigated.

Many studies have investigated the ability of oxidoreductase enzymes to produce chemicals of interest in an electrochemical cell, in a process known as enzymatic electrosynthesis [3,7,13-19]. In such a system, enzymes receive electrons from an electrode either directly or through a chemical mediator, and then catalyze the reduction of their specific substrate to the specific product. Redox polymers have been shown to greatly enhance oxidoreductase activity at the electrode surface through enzyme immobilization and mediation of electron flux to the enzyme [3,20]. Recently characterized redox polymers for enzymatic hydrogen evolution have been either cobaltocene functionalized poly(allylamine) (Cc-PAA) or viologens, due to their low redox potential [3,18,21,22]. An advantage of viologens is the ability to choose from a wide variety of viologen derivatives with different redox potentials. However, many such systems require diffusion of the species for electron transfer to occur, and none have been tested with hydrogenases above ambient temperature. Cobaltocene-functionalized poly(allylamine) has previously been shown to effectively mediate electron transfer to both formate dehydrogenases and hydrogenases for reduction of their respective substrates (Figure 1) [18,23]. The polyallylamine backbone forms a hydrogel when crosslinked with ethylene glycol diglycidyl ether (EGDGE), allowing for enzyme immobilization. Electron transfer can then occur via the cobaltocene functional groups throughout the hydrogel. However, there has been very little research on the ability of redox polymers as mediators for hydrogen evolution by enzymes at elevated temperatures. Given the high specific activity of thermophilic enzymes at elevated temperatures, polymers capable of increasing electron flux to the enzyme at a cathode would further increase activity compared to current electrochemical enzymatic hydrogen evolution reaction (HER) systems.

Here, we demonstrate the hydrogen evolution activity of T. kivui HDCR via direct electron transfer when immobilized at an electrode. We further investigated the capacity of embedding HDCR in a Cc-PAA redox polymer at the cathode and found an enhanced activity of $\mathrm{H}_{2}$ production by more than 340-fold. Further, Cc-PAA mediated hydrogen production occurred at $90 \%$ faradaic efficiency with minimal current loss. Interestingly, HDCR demonstrated reversible inactivation by $\mathrm{CO}$ when in the redox polymer, with most activity being regained after $\mathrm{CO}$ was removed. Cc-PAA is a promising redox polymer for enzyme-mediated, enhanced hydrogen production even at elevated temperatures, making it an auspicious component of new technology for use in chemical storage for renewable energy. 
A

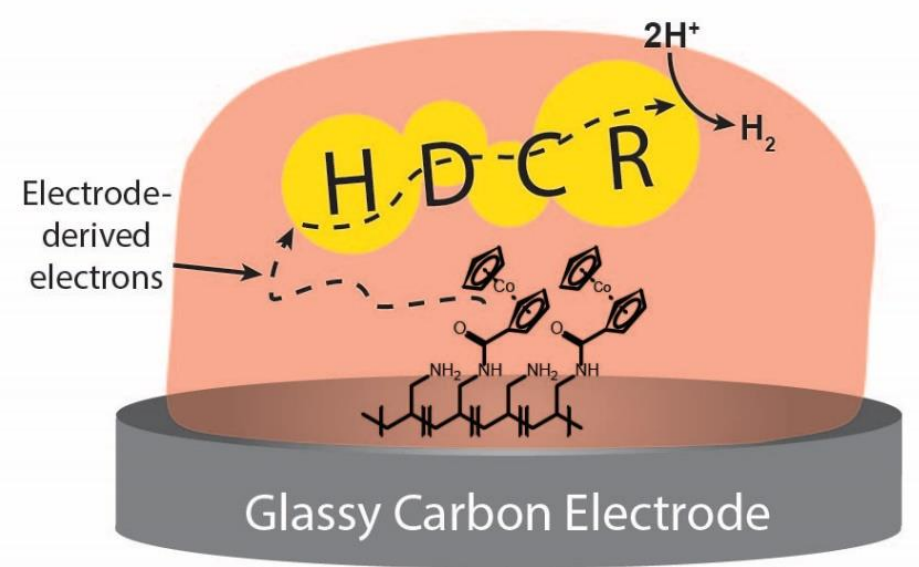

B

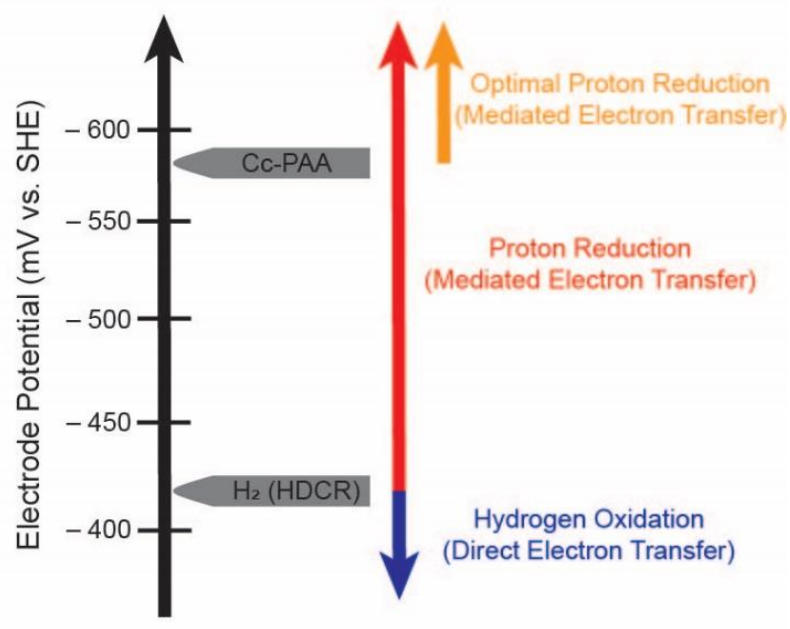

Figure 1. (A) In the mediated electron transfer system, electrons are passed from the electrode through the Cc-PAA redox polymer, with self-exchange between cobaltocene functional groups, before entering the HDCR enzyme for use in hydrogen evolution at the hydrogenase subunit's active site. (B) An energy diagram shows the regimes of hydrogen oxidation and proton reduction in the mediated Cc-PAA/HDCR system. At potentials above the HDCR hydrogenase midpoint potential, direct electron transfer results in a very small oxidative current from hydrogen oxidation at the enzyme. At potentials below the midpoint potential, proton reduction occurs, mediated by Cc-PAA. When the potential is below the midpoint potential of the Cc-PAA, electron transfer to HDCR occurs at the maximum rate.

\section{Results}

\subsection{Optimization of Electrochemical Buffer Conditions}

Electrochemical activity of HDCR was tested first at a 3-electrode, rotating disk electrode (RDE) system. The magnitude of the steady state reductive wave at low potentials of cyclic voltammetry was assumed to be analogous to hydrogen evolution activity as a result of the electrons passing through the electrode for proton reduction. Increasing the temperature of the electrochemical cell from room temperature to $60{ }^{\circ} \mathrm{C}$ resulted in a higher rate of $\mathrm{H}_{2}$ formation but resulted in a higher loss of current density over time (Figure S1). Therefore, an intermediate temperature of $40{ }^{\circ} \mathrm{C}$ was selected for further electrochemical studies, as this temperature displayed similar initial current density as a sample at $60^{\circ} \mathrm{C}$ at a slower loss of activity over time. At $40^{\circ} \mathrm{C}$, the hydrogenase activity was $190 \mu \mathrm{mol} \mathrm{H}{ }_{2} \cdot \min ^{-1} \cdot[\mathrm{mg} \text { protein }]^{-1}$, and the activity of formate dehydrogenase $<1 \mu \mathrm{mol}$ formate $\cdot \mathrm{min}^{-1} \cdot[\mathrm{mg} \text { protein }]^{-1}$. Thus, only electrochemical hydrogen formation was investigated further. As shown in Figure S2A, pH optimization was carried out using HDCR immobilized in Cc-PAA in two different buffers: 1 M sodium citrate with $200 \mathrm{mM}$ potassium chloride for testing a $\mathrm{pH}$ range $4.5-6$, and 1.6 M potassium phosphate with $320 \mathrm{mM}$ sodium chloride for a $\mathrm{pH}$ range $6-7$. The difference in activity observed between both buffers at $\mathrm{pH} 6$ was approximately 4\%. The optimum HDCR activity was at $\mathrm{pH}$ 5.0, allowing for a high concentration of protons in the electrochemical setup. Subsequent assays were conducted using citrate buffer at $\mathrm{pH}$ 5.0, maintaining a 5:1 ratio of sodium citrate to potassium chloride (Figure S2B). An increase in activity with increasing buffer concentration was observed up to the solubility limit of the buffer, resulting in a maximum activity at 2.4 M total solute concentration, with no increase observed in the absence of HDCR. All subsequent electrochemical tests were carried out in the optimal buffer: $2 \mathrm{M}$ sodium citrate, $400 \mathrm{mM}$ potassium phosphate, $\mathrm{pH}$ 5.0. 


\subsection{Hydrogenase Activity Using Methyl Viologen Assays}

Hydrogen evolution activity of HDCR in a chemical assay was determined using methyl viologen as electron mediator. Sodium dithionite showed little reducing activity in the citrate buffer, with no color change of methyl viologen upon the addition of dithionite. This is understandable, given the strong dependence of the sodium dithionite redox potential on temperature, $\mathrm{pH}$, and other environmental factors [24]. Titanium citrate (Ti(III) citrate) showed the ability to reduce methyl viologen at low concentrations of sodium citrate in the buffer but not at high sodium citrate concentrations. It, therefore, was used as the electron donor in a $10 \times$ diluted electrochemistry buffer $(0.2 \mathrm{M}$ sodium citrate, $40 \mathrm{mM}$ sodium chloride), maintaining an excess concentration of Ti(III) citrate. Hydrogen was quantified via GC, and a linear increase in rate was observed (Figure S3). A maximum specific activity of $190 \pm 25 \mu \mathrm{mol} \cdot \mathrm{min}^{-1} \cdot\left[\mathrm{mg}\right.$ protein] ${ }^{-1}$ was observed, which was roughly a 4-fold higher specific activity relative to the Fe-Fe hydrogenase $\mathrm{CpI}$ from mesophilic Clostridium pasteurianum (Figure S4) [18]. Methyl viologen activity assays displayed a similar trend of increasing activity with increasing buffer concentration to that observed in electrochemical buffer optimizations.

\subsection{Cobaltocene-Mediated Hydrogen Evolution in Cyclic Voltammetry Experiments}

Cobaltocene-mediated hydrogen evolution activity was examined using cyclic voltammetry (CV) (Figure 2). HDCR was immobilized in Cc-PAA, and the reductive current at low potentials was measured. A maximum current density of $3.0 \mathrm{~mA} \cdot \mathrm{cm}^{-2}$ was achieved. When cobaltocene was absent, a maximum current density of $8.7 \mu \mathrm{A} \cdot \mathrm{cm}^{-2}$ was observed. Therefore, the presence of cobaltocene resulted in an activity increase of 340-fold, indicating significantly enhanced hydrogen evolution activity. This activity was also compared to inactive, $\mathrm{O}_{2}$-exposed HDCR immobilized in Cc-PAA, and BSA embedded in Cc-PAA as a negative control, both of which displayed significantly lower activities than active HDCR.

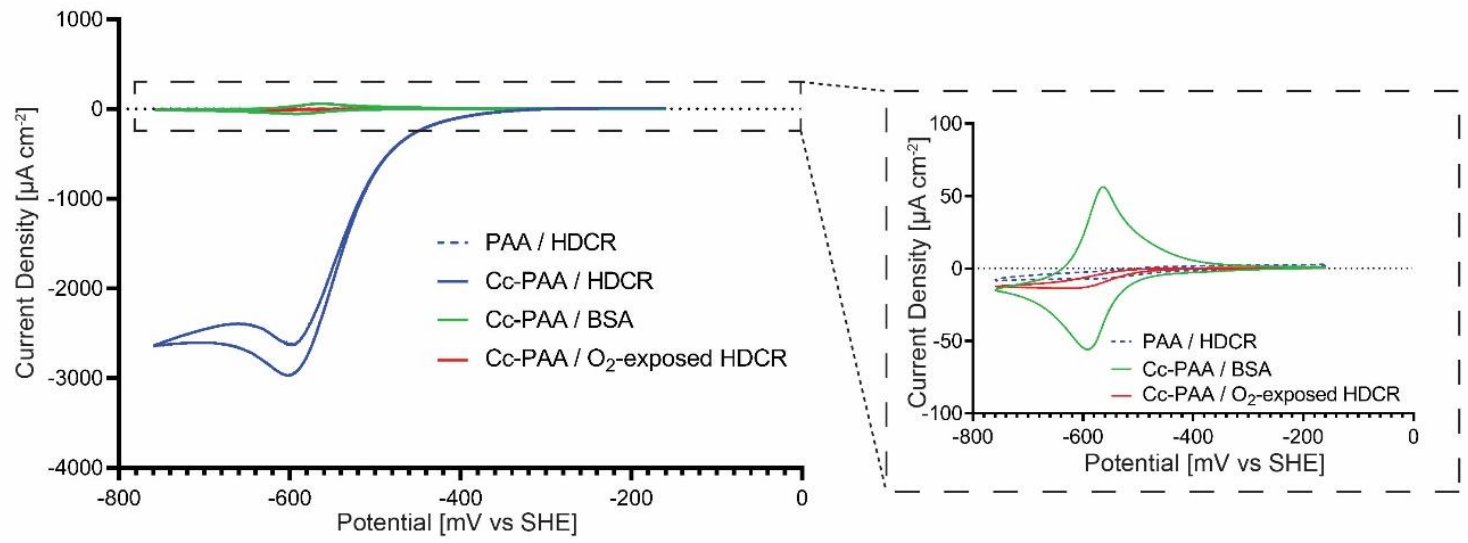

Figure 2. Cyclic voltammetry of HDCR on a rotating disc electrode. A greatly enhanced reductive current at low potentials was observed when cobaltocene-functionalized polyallylamine was present as electron shuttle in the electrode-coating hydrogel. The curve displayed a relatively constant current density with time, at low potentials, which is indicative of mediated enzymatic hydrogen evolution. Inset: Bovine serum albumin (BSA) immobilized in Cc-PAA as a negative activity control showed the expected reduction and oxidation peaks of Cc-PAA. HDCR in non-functionalized polyallylamine and $\mathrm{O}_{2}$-exposed HDCR in Cc-PAA both displayed minimal activities. Rotation rate: $2.83 \mu \mathrm{g}$ HDCR, 2000 RPM, scan rate: $10 \mathrm{mV} / \mathrm{s} . \mathrm{pH} 5,40{ }^{\circ} \mathrm{C}$.

\subsection{Stability of Cc-PAA at Elevated Temperatures}

In both CV and amperometric i-t experiments, reductive current of hydrogen evolution decreased over time. As the enzyme activity appeared to be stable at those temperatures based on methyl viologen assays (Figure S3), we hypothesized that the loss of electrochemical activity was due to an instability of the redox polymer at elevated temperatures. We tested this directly via cyclic voltammetry by monitoring the peak heights of cobaltocene reduction and oxidation at the electrode surface in the absence of HDCR. As shown in 
Figure S5, Cc-PAA stability varied widely with temperature. After $3 \mathrm{~h}$ of continuous cycling, electrodes at $25{ }^{\circ} \mathrm{C}, 40{ }^{\circ} \mathrm{C}$ and $60{ }^{\circ} \mathrm{C}$ retained $79 \%, 32 \%$ and $25 \%$ activity, respectively. Qualitative tests showed that increasing the crosslinker ratio during electrode preparation or increasing the drying time increased stability at high temperatures. However, both experimental variations also resulted in lower initial activity in the presence of HDCR, as seen in Figure S6.

\subsection{Electrochemical Hydrogen Evolution Rates by HDCR and Faradaic Efficiency}

To determine the relationship between observed reductive current and hydrogen produced, quantitative analysis of faradaic efficiency was conducted in closed-system electrochemical H-cells. Amperometric i-t was conducted at a potential of $-650 \mathrm{mV}$ vs. SHE. Hydrogen in the headspace was measured via GC using a thermal conductivity detector, and compared to the theoretical maximum yield, which was calculated from the total current passed through the electrode. Hydrogen production was also measured for a control experiment lacking Cc-PAA (Figure 3). Over a $6.5 \mathrm{~h}$ testing period, hydrogen production rate in the cobaltocene-mediated system $\left(6.24 \mu \mathrm{mol} \cdot \mathrm{mg}\right.$ protein $\left.{ }^{-1} \cdot \mathrm{min}^{-1}\right)$ was, on average, 17 -fold higher than in the cobaltocene-free control $\left(0.365 \mu \mathrm{mol} \cdot \mathrm{mg}\right.$ protein $\left.{ }^{-1} \cdot \mathrm{min}^{-1}\right)$.

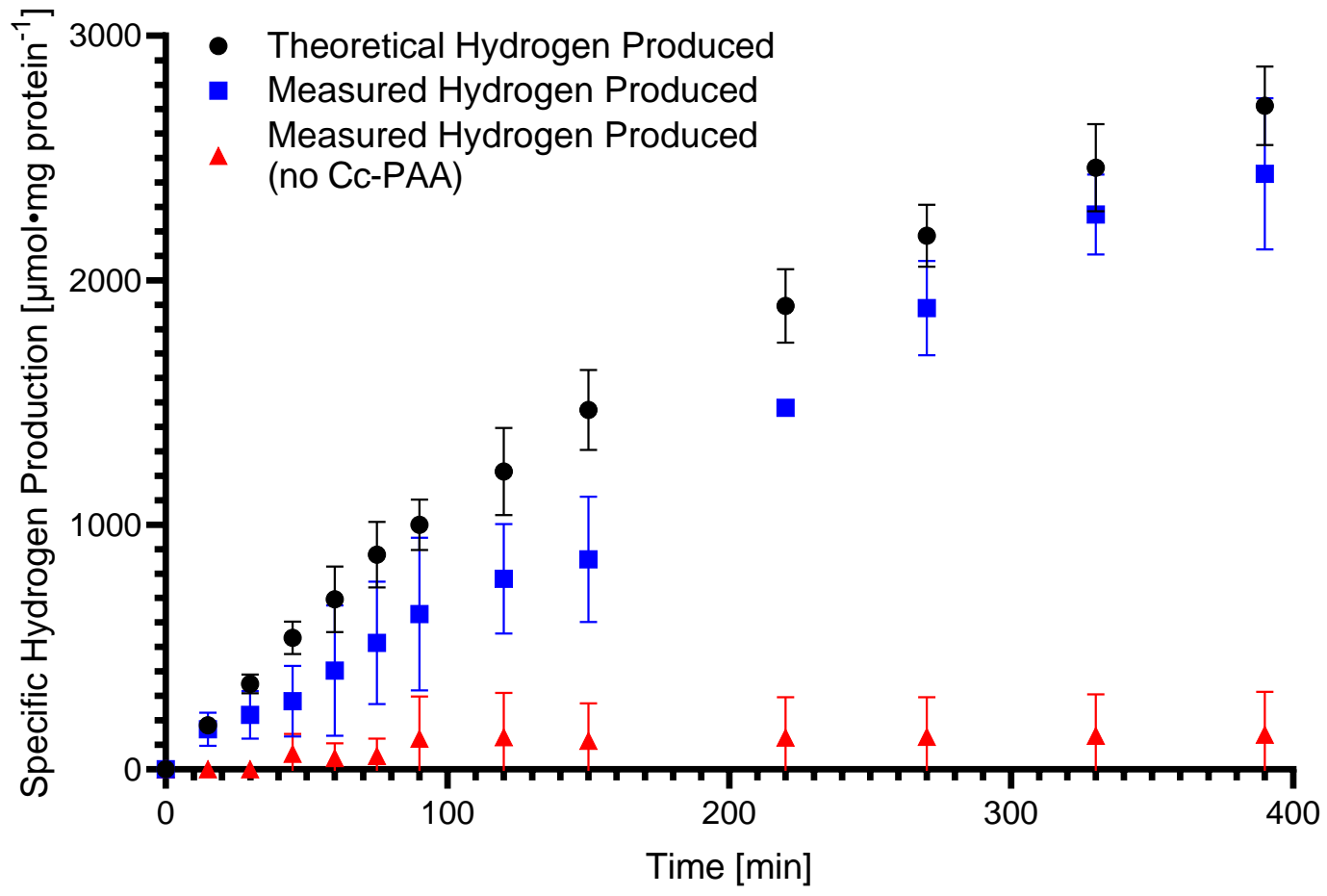

Figure 3. Quantitative comparison of hydrogen produced with and without the presence of Cc-PAA in a closed electrochemical system. Cc-PAA resulted in significantly higher hydrogen production, approaching the maximum theoretical yield based on current passed through the working electrode. Error bars indicate one standard deviation, replicates: $\mathrm{N}=2$. Potential: $-650 \mathrm{mV}$ vs. SHE. $\mathrm{pH} 5,40^{\circ} \mathrm{C}$.

The faradaic efficiency was calculated from the ratio of the measured and theoretical hydrogen yields and is shown in Figure S7. Due to the low hydrogen concentrations at early timepoints, variability in measurements is more visible, resulting in a high apparent variance in efficiency. However, over the time span of the experiment, faradaic efficiency of cobaltocene-mediated hydrogen evolution converged at approximately $90 \%$, showing that reductive waves observed during $\mathrm{CV}$ and reductive currents observed in amperometric $\mathrm{i}-\mathrm{t}$ are useful indicators of hydrogen production. 


\subsection{Reversible HDCR Inactivation by Carbon Monoxide}

The effect of carbon monoxide (CO) on $\mathrm{H}_{2}$-evolution activity of T. kivui HDCR in the Cc-PAA-mediated electrochemical system was tested in an RDE setup using amperometric i-t. A CO-saturated buffer solution was injected into the system to reach an approximate concentration of $10 \mu \mathrm{M} \mathrm{CO}$ in the electrochemical cell and hydrogen evolution (Figure S8) or hydrogen oxidation (Figure 4) was tested. Sodium citrate buffer at pH 5 was used for hydrogen evolution, and potassium phosphate buffer at $\mathrm{pH} 8$ was used for hydrogen oxidation, to make oxidation more thermodynamically favorable. Because the RDE system is intrinsically open to the anoxic atmosphere of the glove box, rotation of the electrode resulted in loss of $\mathrm{CO}$ over time.

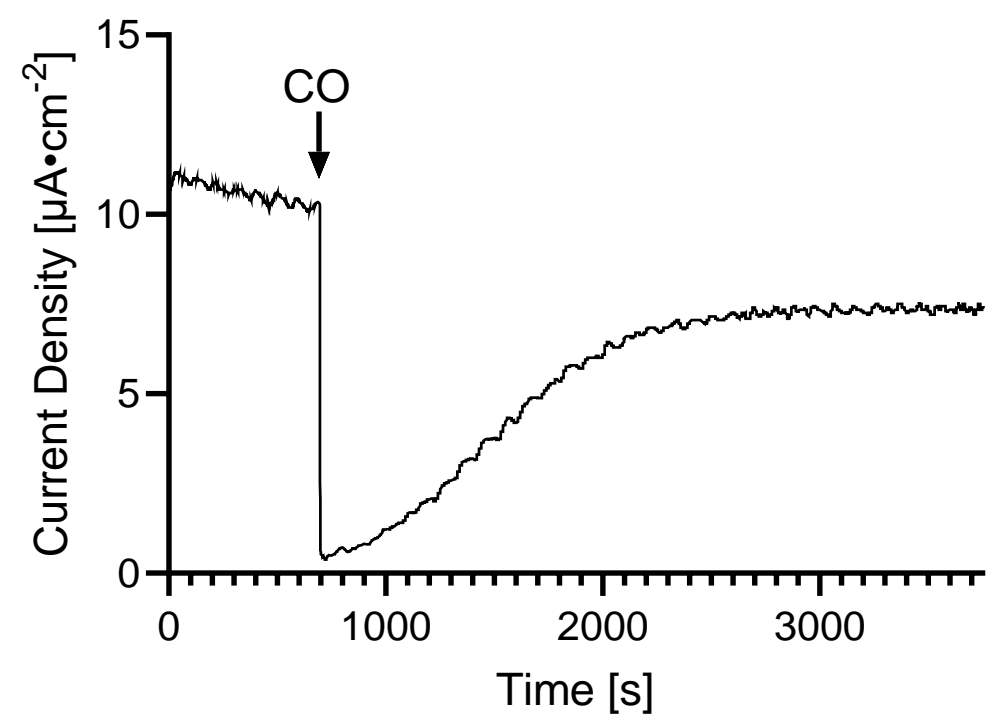

Figure 4. Reversible carbon monoxide inactivation of $\mathrm{HDCR} \mathrm{H}_{2}$ oxidation activity during oxidative amperometric i-t. After initial CO addition, HDCR activity as inferred by current production decreased rapidly, before regaining ca. $75 \%$ of activity over a period of $30 \mathrm{~min}$. Rotation rate: 2000 RPM, potential: $-200 \mathrm{mV}$ vs. SHE. Phosphate buffer, $\mathrm{pH} 8,40^{\circ} \mathrm{C}$.

In both the oxidative and reductive directions, addition of $\mathrm{CO}$ resulted in a sharp reduction of activity after stable current consumption or production. Interestingly, activity slowly recovered to $70-75 \%$ of the original current density, which is indicative of reversible $\mathrm{CO}$ inactivation.

\section{Materials and Methods}

\subsection{Materials and Chemicals}

All chemicals were purchased from Sigma-Aldrich (St. Louis, MO, USA) or Fisher Scientific (Waltham, MA, USA) with the following exceptions: 1-(2,5-dioxopyrrolidinylcarboxy)cobaltocenium hexafluorophosphate was purchased from MCAT (Donaueschingen, Germany). Poly(allylamine) (PAA) (MW 15000, 15\% aq. soln.) was purchased from Polysciences, Inc (Warrington, PA, USA). Ethylene glycol diglycidyl ether (EGDGE) was purchased from Tokyo Chemical Industry (Tokyo, Japan). Glassy carbon working electrodes (GCE) (3 mm diameter), platinum counter electrodes, saturated calomel reference electrodes (SCE), and a CHI1230c potentiostat were purchased from CH Instruments, Inc (Austin, TX, USA). A rotating disk electrode workstation (WaveVortex 10) and glassy carbon rotating disk electrodes ( $5 \mathrm{~mm}$ diameter) were purchased from Pine Research Instrumentation, Inc (Durham, NC, USA). Electrode preparation was conducted in an anoxic chamber (COY Laboratory Products, Inc., Grass Lake, MI, USA) with an $\mathrm{N}_{2} / \mathrm{H}_{2}$ headspace. 


\subsection{HDCR Expression and Purification}

HDCR from T. kivui was produced using the homologous production system as recently described [25]. Therefore, the production strain was grown at $66^{\circ} \mathrm{C}$ under anoxic conditions in complex medium using $1 \mathrm{~L}$ flasks (Müller-Krempel, Bülach, Switzerland) with $500 \mathrm{~mL}$ of media with additional $28 \mathrm{mM}$ glucose and $200 \mu \mathrm{g} \cdot \mathrm{mL}^{-1}$ kanamycin. The preparation of cell-free extract as well as protein purification via nitrilotriacetic acid $\left(\mathrm{Ni}^{2+}\right.$ NTA) resin (Qiagen, Hilden, Germany) were carried out as described before [25]. In contrast, $25 \mathrm{mM}$ of Tris was used in all buffers and the equilibration and elution buffer contained $50 \mathrm{mM}$ and $150 \mathrm{mM}$ imidazole, respectively. Buffer exchange of the eluted and pooled proteins was achieved by ultrafiltration in 100-kDa VIASPIN tubes (Sartorius Stedim Biotech $\mathrm{GmbH}$, Germany) using a buffer composition of $25 \mathrm{mM}$ K-phosphate, $10 \mathrm{mM} \mathrm{MgSO}_{4}, 20 \mathrm{mM} \mathrm{KCl}, 20 \%$ [v/v] glycerol, $2 \mathrm{mM} \mathrm{DTE}, \mathrm{pH}$ 7.0. Aliquots of the purified HDCR enzyme were frozen in liquid nitrogen and stored at $-80^{\circ} \mathrm{C}$ [10].

\subsection{Synthesis of Cobaltocene-Functionalized Poly(allylamine) (Cc-PAA) \\ Cc-PAA was synthesized as previously described [18].}

\subsection{Preparation of HDCR-Embedded Electrodes}

The HDCR/Cc-PAA enzymatic electrode was prepared via drop casting $11 \mu \mathrm{L}$ of a solution containing $7 \mu \mathrm{L}$ Cc-PAA $(5 \mathrm{mg} / \mathrm{mL}), 2.3 \mu \mathrm{L}$ EGDGE $(10 \% v / v)$, and $2.3 \mu \mathrm{L}$ of HDCR $(1.3 \mathrm{mg} / \mathrm{mL})$ onto a polished glassy carbon electrode $(5 \mathrm{~mm}$ diameter). The electrode was then dried for $75 \mathrm{~min}$ before testing. The HDCR/PAA enzymatic electrode used the same mixture, substituting poly(allylamine) (PAA) $(5 \mathrm{mg} / \mathrm{mL})$ in place of Cc-PAA. The BSA/Cc-PAA electrode was prepared by drop casting $11 \mu \mathrm{L}$ of a solution containing $7 \mu \mathrm{L} \mathrm{Cc}-\mathrm{PAA}(5 \mathrm{mg} / \mathrm{mL}), 2.3 \mu \mathrm{L}$ EGDGE $(10 \% v / v)$, and $2.3 \mu \mathrm{L}$ of BSA $(2 \mathrm{mg} / \mathrm{mL})$, followed by 75 min of drying before use. $\mathrm{O}_{2}$-exposed HDCR was prepared by incubating HDCR in a conical centrifuge tube open to air at room temperature for $30 \mathrm{~min}$. Bulk electrolysis enzymatic electrodes were prepared by drop casting $5.5 \mu \mathrm{L}$ of the solution described above on a polished glassy carbon electrode ( $3 \mathrm{~mm}$ diameter), followed by drying for $75 \mathrm{~min}$. Cobaltocene-free bulk electrolysis controls were prepared using $5.5 \mu \mathrm{L}$ of a solution containing $2.3 \mu \mathrm{L} \mathrm{HDCR}$ and $9.3 \mu \mathrm{L} \mathrm{BSA}$, to aid in protein immobilization and minimize side reactions occurring on the exposed glassy carbon surface.

\subsection{Electrochemical Methods}

Rotating disk studies were performed with a WaveVortex ${ }^{\circledR}$ electrode rotator (Pine Research Instrumentation, Durham, NC, USA). Studies used an SCE reference electrode, GCE working electrode, and platinum mesh counter electrode in a three-electrode configuration. All potentials are reported relative to the standard hydrogen electrode (SHE) $\left(\mathrm{E}^{0} \mathrm{SHE}=\mathrm{E}^{0} \mathrm{SCE}+0.242 \mathrm{~V}\right)$. Electrode preparation and testing were done in an anoxic glove bag. Preparation occurred at room temperature and tests were conducted at the temperatures indicated.

Bulk electrolysis experiments were completed using an airtight H-cell (Adams and Chittenden, Berkeley, CA, USA) with a Nafion ${ }^{\circledR}$ proton exchange membrane. A silver/silver chloride $(\mathrm{Ag} / \mathrm{AgCl})$ reference electrode, glassy carbon disk working electrode, and graphite rod counter electrode were used. Potentials were reported relative to the $\operatorname{SHE}\left(\mathrm{E}_{\mathrm{SHE}}^{0}=\mathrm{E}_{\mathrm{Ag} / \mathrm{AgCl}}^{0}+0.197 \mathrm{~V}\right)$. Electrode preparation was done in an anoxic glove bag at room temperature, and testing was conducted at $40{ }^{\circ} \mathrm{C}$, after flushing for $20 \mathrm{~min}$ with $100 \% \mathrm{~N}_{2}$. Tests were completed using a VMP3 potentiostat (Biologic Science Instruments, Seyssinet-Pariset, France).

\subsection{Synthesis of Ti(III) Citrate}

Ti(III) citrate was synthesized as previously described [26], with the following modification: $\mathrm{pH}$ adjustment to $\mathrm{pH} 7.0$ was completed with $1 \mathrm{M} \mathrm{NaOH}$ in place of sodium carbonate. 


\subsection{Methyl Viologen Assay for Quantification of Chemical Hydrogen Evolution Rates}

Chemical hydrogen evolution activity assays were carried out using $5 \mathrm{~mL}$ liquid samples with $5 \mathrm{~mL}$ headspace in sealed vials. The indicated buffer solutions were combined with $2 \mathrm{mM}$ methyl viologen and $10 \mathrm{mM}$ electron donor. For phosphate buffered samples, sodium dithionite was used as the electron donor. For citrate buffered samples, Ti(III) citrate was used as the electron donor. Vials were flushed with nitrogen for $10 \mathrm{~min}$, followed by addition of HDCR, and incubated at $40^{\circ} \mathrm{C}$. Hydrogen concentration in the headspace was measured by gas chromatography (GC).

\section{Discussion and Conclusions}

Cc-PAA was previously found to enhance hydrogen electrosynthesis by hydrogenases, with 20- to 40-fold increase in reductive current densities compared to the absence of the redox polymer [18]. In this work, we showed that Cc-PAA, paired with HDCR of thermophilic T. kivui, increased current density 340-fold in an RDE system. This resulted in maximum current densities of approximately $3 \mathrm{~mA} \cdot \mathrm{cm}^{-2}$-an unprecedented activity that is significantly higher than previously reported current densities in mediated enzymatic electrochemical hydrogen evolution systems, particularly in systems which contain hydrogen in the headspace $[18,22]$. In closed-system electrochemical hydrogen experiments, Cc-PAA increased hydrogen production by 17 -fold. This difference in activity increase can be attributed to several factors, including primarily mass transfer limitations in the closed-system H-cells which were mixed using stir bars rather than an RDE, and lower apparent specific activity due to loss of enzyme activity over the extended course of the 6.5-h test. Despite the heat inactivation of Cc-PAA, approximately $90 \%$ faradaic efficiency was maintained over the 6.5 -h testing period. This confirms that at elevated temperatures, Cc-PAA continues to supply electrons to embedded enzymes with high specificity even when partially degraded.

CO inactivation of HDCR was largely reversible, with a fast inactivating step followed by a gradual reactivating step, with $70-75 \%$ recovery of activity. This important finding shows promise for the use of this enzyme in CO-containing systems such as syngas utilizing processes. Additional optimization of the system may allow for this recovery to be improved further. While the enzyme preparation used had a bias for hydrogenase activity, given the previously demonstrated activity of the enzyme to catalyze the reaction in either direction in nonelectrochemical settings, it is hypothesized that electron mediation via Cc-PAA to fully active HDCR would also result in $\mathrm{CO}_{2}$ reduction to formate. If this is the case, it would allow for the production of a highly soluble energy carrier at high rates, and should be investigated in future work [27]. The presented data show that Cc-PAA in conjunction with the T. kivui HDCR acts as a highly effective catalyst for hydrogen production, achieving both high current densities and high specificity. This demonstrates an important improvement in catalytic current density of a mediated enzymatic hydrogen evolution system, further optimization of which will allow for industrially relevant rates and volumes to be achieved, aiding in the search for sustainable hydrogen catalysis.

Supplementary Materials: The following are available online at https:/ / www.mdpi.com/article/10 .3390 / catal11101197/s1, Figure S1. Activity comparison of HDCR activity in Cc-PAA at different temperatures. A: $25^{\circ} \mathrm{C}, \mathrm{B}: 30^{\circ} \mathrm{C}, \mathrm{C}: 40^{\circ} \mathrm{C}, \mathrm{D}: 60^{\circ} \mathrm{C}$. Tests at $40^{\circ} \mathrm{C}$ showed high activity, but with less activity loss over time compared to higher temperatures. Phosphate buffer, pH 6, Figure S2. $\mathrm{pH}$ and buffer concentration optimizations revealed an optimal $\mathrm{pH}$ of 5.0 and higher activities at increasing buffer concentrations. (A) Comparison of the magnitude of the reductive wave for electrochemical hydrogen evolution in buffers of different $\mathrm{pH}$. Citrate buffer was used for $\mathrm{pH} 6$ and below, and phosphate buffer for $\mathrm{pH} 6$ and above, with negligible difference between the buffers at $\mathrm{pH} 6$. (B) Citrate buffer had a molar ratio of 5:1 sodium citrate: $\mathrm{KCl}$, and this ratio was maintained across all solute concentrations. Activity increased with increasing solute concentration up to the solubility limit of the buffer-a similar trend to that observed in previous FeFe hydrogenase, cobaltocenemediated systems [1]. Rotation rate: $2000 \mathrm{RPM}$, scan rate: $10 \mathrm{mV} / \mathrm{s}$. Replicates: N = 3, Figure S3. Specific hydrogen production by HDCR in $0.2 \mathrm{M}$ sodium citrate and $40 \mathrm{mM} \mathrm{KCl}, \mathrm{pH} 5.0$, when 
mediated by methyl viologen with $\mathrm{Ti}(\mathrm{III})$ citrate as electron donor. Similar trends at different rates were observed in phosphate buffer and HEPES buffer, both at pH 6 with dithionite as the electron donor. Test completed at $40{ }^{\circ} \mathrm{C}$. Replicates: $\mathrm{N}=3$, Figure S4. HDCR displayed high specific activities for methyl viologen mediated hydrogen evolution, compared to previously reported hydrogenases in their respective optimal electrochemistry buffers [1]. Replicates: $\mathrm{N}=3$, Figure S5. Cobaltocene redox peak magnitude is lost over time at increasing rates with increasing temperature. Of the tested temperatures, Cc-PAA shows the highest stability at $25^{\circ} \mathrm{C}(\mathrm{A})$, intermediate stability at $40{ }^{\circ} \mathrm{C}(\mathrm{B})$, and lowest stability at $60^{\circ} \mathrm{C}(\mathrm{C})$. Note the different time scale between panels- $12 \mathrm{~h}$ for $\mathrm{A}$ and $\mathrm{B}, 4 \mathrm{~h}$ for $\mathrm{C}$. Cycles are normalized for the maximum magnitude achieved at each temperature, respectively. Rotation rate: $2000 \mathrm{RPM}$, scan rate: $10 \mathrm{mV}$ /s. pH 5, Figure S6. Increasing crosslinker ratio resulted in less activity loss over time, but with a lower initial activity. Data shown is the magnitude of the reductive wave during cyclic voltammetry of HDCR embedded in Cc-PAA with the usual crosslinker ratio as "low" and a $2 \times$ crosslinker concentration as "high". Timepoint 1: $1 \mathrm{~min}$; timepoint 2: $29 \mathrm{~min}$. pH 5, Figure S7. Faradaic efficiency of Cc-PAA-mediated HDCR approached $90 \%$ over extended testing periods. Large error bars at early timepoints are due to variation in measurements at very low hydrogen concentrations. Error bars indicate one standard deviation. Replicates: $\mathrm{N}=2 . \mathrm{pH} 5,40{ }^{\circ} \mathrm{C}$, Figure S8. Carbon monoxide inactivation during reductive amperometric i-t of Cc-PAAembedded HDCR displayed an initial strong decrease in activation before regaining activity to a stable value. Subsequent additional inactivation resulted in another initial loss of activity, followed by ca. $70 \%$ of activity being regained. Rotation rate: $2000 \mathrm{RPM}$, potential: $-650 \mathrm{mV}$ vs. SHE. Citrate buffer, $\mathrm{pH} 5,40{ }^{\circ} \mathrm{C}$.

Author Contributions: The manuscript was written through contributions of all authors. Conceptualization, A.M.S. and V.M.; methodology, A.M.S., V.M., J.C.R. and F.M.S.; formal analysis, J.C.R.; investigation, J.C.R. and F.M.S.; resources, A.M.S., V.M., J.C.R. and F.M.S.; data curation, J.C.R.; writing-original draft preparation, J.C.R.; writing-review and editing, A.M.S., V.M., J.C.R. and F.M.S.; visualization, A.M.S. and V.M.; supervision, A.M.S. and V.M.; project administration, A.M.S.; funding acquisition, A.M.S. and V.M. All authors have read and agreed to the published version of the manuscript.

Funding: Work in the Spormann lab was funded by the Achievement Rewards for College Scientists (ARCS) Foundation and the Stanford Global Climate and Energy Project (GCEP). Work from the Müller lab was funded by the European Research Council (ERC) under the European Union's Horizon 2020 research and innovation program (grant agreement 741791).

Acknowledgments: We gratefully acknowledge the Spormann Laboratory at Stanford University, the Müller lab at Johann Wolfgang Goethe University in Frankfurt am Main, and Ross D. Milton, University of Geneva, for useful discussions.

Conflicts of Interest: The authors declare no competing financial interests.

$\begin{array}{ll}\text { Abbreviations } \\ \text { HDCR } & \text { Hydrogen-Dependent } \mathrm{CO}_{2} \text { Reductase; } \\ \text { Cc-PAA } & \text { cobaltocene-functionalized poly(allylamine); } \\ \text { RDE } & \text { rotating disk electrode; } \\ \text { SHE } & \text { standard hydrogen electrode; } \\ \text { CV } & \text { cyclic voltammetry. }\end{array}$

\section{References}

1. Lindstrom, P.; Fritsch, D.; Fickling, M.; Chase, N.; Martin, L.; Anti, L.; Hansom, S.; Gross, P.; Palguta, J.; Dyl, K.; et al. Annual Energy Outlook 2020; U.S. Energy Information Administration: Washington, DC, USA, 2020.

2. Dresselhaus, M.S.; Thomas, I.L. Alternative energy technologies. Nature 2001, 414, 332-337. [CrossRef]

3. Ruth, J.C.; Spormann, A.M. Enzyme Electrochemistry for Industrial Energy Applications-A Perspective on Future Areas of Focus. ACS Catal. 2021, 11, 5951-5967. [CrossRef]

4. Abe, J.O.; Popoola, A.P.I.; Ajenifuja, E.; Popoola, O.M. Hydrogen energy, economy and storage: Review and recommendation. Int. J. Hydrogen Energy 2019, 44, 15072-15086. [CrossRef]

5. Gotovsky, M.A.; Gotovsky, A.M.; Mikhailov, V.E.; Lychakov, V.D.; Sukhorukov, Y.G.; Sukhorukova, E.A. Formate: The Third Way in Green Energy. Int. J. Chem. Eng. Appl. 2019, 10, 189-194. [CrossRef] 
6. $\quad$ Blanco, H.; Cazzola, P.; Dulac, J.; Fukui, H.; Kim, T.-Y.; Kurban, Z.; Levi, P.; Malischek, R.; McGlade, C.; Petrosyan, K.; et al. The Future of Hydrogen; International Energy Agency: Paris, France, 2019.

7. Cadoux, C.M.; Milton, R.D. Recent enzymatic electrochemistry for reductive reactions. ChemElectroChem 2020, 7, 1974-1986. [CrossRef]

8. Ceccaldi, P.; Schuchmann, K.; Müller, V.; Elliott, S.J. The Hydrogen Dependent $\mathrm{CO}_{2}$ reductase: The first completely co tolerant fefe-hydrogenase. Energy Environ. Sci. 2017, 10, 503-508. [CrossRef]

9. Schwarz, F.M.; Ciurus, S.; Jain, S.; Baum, C.; Wiechmann, A.; Basen, M.; Müller, V. Revealing formate production from carbon monoxide in wild type and mutants of Rnf- and Ech-containing acetogens, Acetobacterium woodii and Thermoanaerobacter kivui. Microb. Biotechnol. 2020, 13, 2044-2056. [CrossRef]

10. Schwarz, F.M.; Schuchmann, K.; Müller, V. Hydrogenation of $\mathrm{CO}_{2}$ at ambient pressure catalyzed by a highly active thermostable biocatalyst. Biotechnol. Biofuels 2018, 11, 237. [CrossRef]

11. Müller, V. New Horizons in Acetogenic Conversion of One-Carbon Substrates and Biological Hydrogen Storage. Trends Biotechnol. 2019, 37, 1344-1354. [CrossRef]

12. Lubitz, W.; Ogata, H.; Rudiger, O.; Reijerse, E. Hydrogenases. Chem. Rev. 2014, 114, 4081-4148. [CrossRef]

13. Lienemann, M.; Deutzmann, J.S.; Milton, R.D.; Sahin, M.; Spormann, A.M. Mediator-free enzymatic electrosynthesis of formate by the Methanococcus maripaludis heterodisulfide reductase supercomplex. Bioresour. Technol. 2018, 254, 278-283. [CrossRef]

14. Basso, A.; Serban, S. Industrial applications of immobilized enzymes-A review. Mol. Catal. 2019, 479, 110607. [CrossRef]

15. Srikanth, S.; Alvarez-Gallego, Y.; Vanbroekhoven, K.; Pant, D. Enzymatic Electrosynthesis of Formic Acid through Carbon Dioxide Reduction in a Bioelectrochemical System: Effect of Immobilization and Carbonic Anhydrase Addition. ChemPhysChem 2017, 18, 3174-3181. [CrossRef]

16. Sakai, K.; Kitazumi, Y.; Shirai, O.; Takagi, K.; Kano, K. Efficient bioelectrocatalytic $\mathrm{CO}_{2}$ reduction on gas-diffusion-type biocathode with tungsten-containing formate dehydrogenase. Electrochem. Commun. 2016, 73, 85-88. [CrossRef]

17. Lee, C.-Y.; Park, H.S.; Fontecilla-Camps, J.C.; Reisner, E. Photoelectrochemical $\mathrm{H}_{2}$ Evolution with a Hydrogenase Immobilized on a $\mathrm{TiO}_{2}$-Protected Silicon Electrode. Angew. Chem. Int. Ed. 2016, 55, 5971-5974. [CrossRef]

18. Ruth, J.C.; Milton, R.D.; Gu, W.; Spormann, A.M. Enhanced Electrosynthetic Hydrogen Evolution by Hydrogenases Embedded in a Redox-Active Hydrogel. Chem. Eur. J. 2020, 26, 7323-7329. [CrossRef] [PubMed]

19. Morra, S.; Valetti, F.; Sarasso, V.; Castrignanò, S.; Sadeghi, S.J.; Gilardi, G. Hydrogen production at high Faradaic efficiency by a bio-electrode based on $\mathrm{TiO}_{2}$ adsorption of a new [FeFe]-hydrogenase from Clostridium perfringens. Bioelectrochemistry 2015, 106, 258-262. [CrossRef] [PubMed]

20. Ruff, A. Redox polymers in bioelectrochemistry: Common playgrounds and novel concepts. Curr. Opin. Electrochem. 2017, 5, 66-73. [CrossRef]

21. Hardt, S.; Stapf, S.; Filmon, D.T.; Birrell, J.A.; Rüdiger, O.; Fourmond, V.; Léger, C.; Plumeré, N. Reversible H2 oxidation and evolution by hydrogenase embedded in a redox polymer film. Nat. Catal. 2021, 4, 251-258. [CrossRef] [PubMed]

22. Shiraiwa, S.; So, K.; Sugimoto, Y.; Kitazumi, Y.; Shirai, O.; Nishikawa, K.; Higuchi, Y.; Kano, K. Reactivation of standard [NiFe]-hydrogenase and bioelectrochemical catalysis of proton reduction and hydrogen oxidation in a mediated-electron-transfer system. Bioelectrochemistry 2018, 123, 156-161. [CrossRef] [PubMed]

23. Yuan, M.; Sahin, S.; Cai, R.; Abdellaoui, S.; Hickey, D.P.; Minteer, S.D.; Milton, R.D. Creating a Low-Potential Redox Polymer for Efficient Electroenzymatic $\mathrm{CO}_{2}$ Reduction. Angew. Chem. Int. Ed. 2018, 57, 6582-6586. [CrossRef] [PubMed]

24. Mayhew, S.G. The Redox Potential of Dithionite and $\mathrm{SO}_{2}^{-}$from Equilibrium Reactions with Flavodoxins, Methyl Viologen and Hydrogen plus Hydrogenase. Eur. J. Biochem. 1978, 85, 535-547. [CrossRef] [PubMed]

25. Katsyv, A.; Schoelmerich, M.C.; Basen, M.; Müller, V. The pyruvate:ferredoxin oxidoreductase of the thermophilic acetogen, Thermoanaerobacter kivui. FEBS Open Bio 2021, 11, 1332-1342. [CrossRef] [PubMed]

26. Zehnder, A.J.B.; Wuhrmann, K. Titanium(III) citrate as a nontoxic oxidation-reduction buffering system for the culture of obligate anaerobes. Science 1976, 194, 1165-1166. [CrossRef]

27. Sidgwick, N.V.; Gentle, J.A.H.R. CCXX1.-The Solubilities of the Alkali Formates and Acetates in Water. J. Chem. Soc. 1922, 1837-1843. [CrossRef] 